\title{
A Brief Analysis on the Ways to "Etiquette -Based Kindergarten Management" —_Based on A Survey of Kindergartens in XX Town
}

\author{
Qiong Feng \\ Jinjiang College, Sichuan University, Meishan, Sichuan, China
}

\begin{abstract}
In our country of etiquette, etiquette has long served as an important means for social regulation. Nowadays, in the era of reviving Chinese traditional culture, etiquette can still play an important role in the management of various organizations. "Etiquette-based kindergarten management" is to take etiquette as a means of kindergarten management, which is practiced through full participation of kindergarten administrators, kindergarten teachers, children, logistics, and parents in five layers from the three aspects of etiquette, etiquette system, and etiquette education. By forming the atmosphere of knowing etiquette, observing etiquette and using etiquette from top to bottom in the kindergarten, it thereby achieves the purpose of constructing a harmonious and warm kindergarten.
\end{abstract}

Keywords: Etiquette-based management, kindergarten, respect

\section{Background}

1.1 The concept of traditional "rule by etiquette"

Traditional China is known for its "rule by etiquette", and etiquette has long become the most important means of social regulation in China [1]. As the saying goes, "the people are governed if etiquette is promoted, and the people are in chaos if etiquette is abolished." [2]. The "rule of etiquette" as a general strategy of China's state governance already appeared in the Xia and Shang era, which was perfected through duke of Zhou's system of etiquette. "While Zhou people inherited the bronze culture of the Yin people, they made a qualitative leap in the field of ideology, thus incorporating all of human life and social life into the category of etiquette, forming a complete system at the conceptual and institutional level, which represents a huge progress in making society turn from rule by witchcraft to rule by etiquette."[3].

It can be said that "the ideological system of "rule by etiquette" is an ideology system that takes morality as ideal, system of rites, etiquette as norms, and adopts education and punishment (that is, rite, music, punishment, and politics in ancients' saying) to comprehensively govern the country. It not only summarizes the thoughts of Xia and Shang's rule by etiquette, but also practices system of the Western and Zhou Dynasties. Its characteristic is to maintain the main line of "harmony" and "respect", which also involves various aspects such as theocracy and traditional customs."[4].The so-called "rule by etiquette", to put it simply, means maintaining and coordinating human relations and hierarchical relationships through content and methods such as "etiquette system", "etiquette", and "etiquette instruments", thereby achieving social stability and solid governance [5].

\subsection{Creative transformation of etiquette}

China's traditional society is a society of acquaintances and a society based on "rule by etiquette", which was nurtured in a long rural society. The rule by etiquette can be implemented largely because "the rural society is a society in which one was born here, grew up here, and died here. It not only had very small population movement, but also the land from which people acquired resources rarely changed. In this environment that excludes changes despite evolution of dynasties, individuals can not only trust their own experience, but also the experience of

ISSN: 0010-8189

(C) CONVERTER 2020

www.converter-magazine.info 
ancestors. An old farmer who farmed in a rural society experienced merely the changes of seasons, rather than changes of the times. Such phenomena went round and round. The solutions used by the predecessors to solve life problems can be copied as a guide for descendants' lives. What's proved as effective in the previous generations' lives is more worthy of preservation. In this way, "obedience to Yao and Shun", respect for ancient is the guarantee of life."[6].

However, "the rule by etiquette must be based on the premise that tradition can effectively cope with life problems. Rural society meets this premise, because its order can be maintained by etiquette. In a rapidly changing society, the effectiveness of tradition cannot be guaranteed. No matter how effective a way of living has been in the past, if the environment changes, no one can use the old methods to deal with new problems anymore."

Today's society is in an era of globalization and intelligence. On the one hand, "in our real life, the negative effects and legacy of etiquette tradition still exist. The patriarchal and hierarchical nature of etiquette, and the resulting concept of subordination represses, distorts human nature. Also, there is value orientation of "agriculture first and commerce second", the principle of "preserving the sacrificial sheep needed for etiquette", and the resulting formalism of emphasizing rules and regulations, the conservative psychology of following the beaten track; various out-of-date and even harmful "game rules" derived from "etiquette"... These still plague the Chinese people in their move toward modern life in varying degrees."

On the other hand, "in the face of the new challenges of the Internet age, the rule by etiquette can help rebuild integrity, stability, and certainty of ethical entities such as individuals, family, society, and the country." [7].

President $\mathrm{Xi}$ pointed out that we need "creatively transform and innovatively develop the excellent Chinese traditional culture."[8]. "Since it is talking about transformation of tradition rather than redintegration, the transformation of the cultural tradition of etiquette by no means mean to restore or return to the ancient rule by etiquette."

We must abandon the bad influence of class nature and human nature repression in traditional etiquette-based governance, and give play to the role of traditional etiquette culture in maintaining good social order and harmonious interpersonal relationships. Therefore, "reconstruction of traditional etiquette is definitely to integrate Chinese traditional culture with modern civilization, and reconstruct family ethical order based on autonomy and equality. The traditional etiquette should also be reconstructed on the premise of maintaining individual dignity and value, thus abandoning content unsuitable for modern society, retaining the connotation that can showcase family affection and modern value, preserving Chinese etiquette characteristics, seeking and answering "what is a good life"[9].

\subsection{The concept of "etiquette-based kindergarten management"}

Etiquette-based kindergarten management is a model that combines traditional etiquette with modern one in kindergarten management. It aims to cultivate gentlemen and ladies who are independent, innovative, dare to express and seek win-win cooperation. Practiced among kindergarten administrators, kindergarten teachers, children, logistics, and parents through the three aspects of etiquette, etiquette system, and etiquette education, it makes the kindergarten form the atmosphere of knowing etiquette, observing etiquette, and using etiquette from top to bottom, thereby achieving harmony between oneself and others, and constructing a warm and harmonious kindergarten environment.

\section{The role and significance of "etiquette-based kindergarten management"}

\subsection{Build a harmonious kindergarten atmosphere}

ISSN: 0010-8189

(C) CONVERTER 2020

www.converter-magazine.info 
There are 41 kindergartens in XX Town, including 5 public kindergartens, 36 private kindergartens and charity kindergartens. In the past four years, it has been reported from time to time that in these private kindergartens, "kindergarten chairman assaulted kindergarten teachers", "kindergarten teacher acupunctured children", and "more than 50 children suffered from formaldehyde poisoning". Such situation not only inflicted indelible physical and mental damage to children, making parents reluctant to send their children to the kindergarten, but also caused irreparable loss of image to the kindergartens.

"People have four moods, and the function of etiquette is to make them "justly express emotions" ("The Doctrine of the Mean"), that is, just right without causing harm to others."[10]. Regardless of kindergarten teachers or administrators, one need handle emotions properly, thus treating others with "gentle voice and attitude". In this way, "etiquette-based kindergarten management" can enable harmonious relationship between the administrator and the kindergarten teacher, between the kindergarten teacher colleagues, and between the kindergarten teacher and the children, thus building a more harmonious kindergarten, so that children grow up healthily in a pleasant atmosphere.

\subsection{Improve the staff quality and enhance the kindergarten image}

The party and the state pointed out in the "Opinions on the Implementation of the Inheritance and Development Project of Chinese Excellent Traditional Culture": "we should strengthen national etiquette education, highlight the era value of Chinese traditional etiquette culture, and establish a good image as an ancient civilization and a country of etiquette, establish and improve etiquette, protocol, and politeness norms in various public places and online public spaces, promote the formation of good behavior as well as courteous and tolerant social customs.[11].

Administrators, kindergarten teachers, logistics and other staff should create an image that fits their own identity through the learning and practice of etiquette knowledge, display the optimal mental outlook, and adopt appropriate interpersonal communication methods. This not only improves the quality of kindergarten staff, but also enhances the kindergarten's image.

\subsection{Cultivate well-mannered children and form good social customs}

Children aged 3-6 are highly plastic and can easily accept various information from the outside world. It is a good time to learn etiquette knowledge and develop good behavior habits. The kindergarten staff, especially the kindergarten teachers, are the objects of children's contact and imitation, and children will learn methods of interaction with others from them. If the kindergarten teacher treats others with courtesy, then the children will also be positively affected in subtle ways. In addition, the kindergarten should integrates etiquette knowledge in kindergarten running idea, curriculum content design, kindergarten environment layout, and arrangement of various activities to promote children's physical and mental health, so that the children get along with others in harmony, abide by the social rules, and form a civilized and courteous behavior mode.

\section{Ways to "Etiquette-based Kindergarten Management"}

3.1 One center: set up etiquette teaching content around training goals

Kindergartens should always manage and set up etiquette teaching content and teaching methods around the training goals. The purpose of "etiquette-based kindergarten management" is to train children to be independent, innovative, future-oriented gentlemen and ladies daring to express with win-win cooperation. There is need to avoid the mistake of formalism in efforts to become etiquette-based kindergarten.

3.2 Three aspects: Effectively ensure the popularization and implementation of etiquette knowledge

ISSN: 0010-8189 


\subsubsection{Personal self-internalization}

Regardless of administrator, logistic staff, kindergarten teacher, children or parents, everyone must first cultivate one's morality with etiquette and achieve harmony with oneself. Individuals are the main body participating in the social operation. Only when everyone in the organization practices etiquette can the harmonious order of the entire organization be realized. "Etiquette is a code of behavior for playing a role in society. "Cultivating one's morality with etiquette" enables transformation of a "natural person" into a "social person", but self-cultivation is not the ultimate goal. The ultimate goal of self-cultivation is to participate in social life and assume social roles."[12]. If every staff member of the kindergarten always keeps his own identity in mind, speaks and acts in line with his own role, kindergartens will have less occurrence of adverse events such as beating, scolding and abuse of children by kindergarten teachers, conflicts between administrators and kindergarten teachers.

Secondly, individuals should use appropriate expressions to get along with others in harmony and cooperate for a win-win situation. The kindergarten staff should follow the etiquette rules, treat others with courtesy, and set a good example for the children. As a teaching unit, kindergartens should cultivate children's independent, innovative, and cooperative way of thinking and behavior, so that children respect their parents but refuse blind filial piety, respect teachers but not blindly follow them, respect partners without pleasing them. In this way, children develop independent thinking and problem-solving skills, and enjoy a unique life experience in the kindergarten.[13]

\subsubsection{Collective etiquette education}

"Etiquette demands teaching."[14]. "The key to civilization inheritance is to help society members understand etiquette, practice etiquette, obey the rules, have a bottom line, and become a civilized person. Education takes etiquette as an important content, and the implementation and popularization of etiquette are inseparable from education or enlightenment of social communities including society, family, school, government, etc. Therefore, the bond between etiquette and education to form etiquette education is a sign of cultural maturity. The inheritance of culture cannot ignore the inheritance of etiquette education."

Enlightenment is the most extensive governance method in the rule of virtue, which can not only penetrate into people's words and deeds, but also penetrate into people's hearts. Enlightenment is also an important auxiliary means to realize the rule of etiquette and the rule of law, because people embracing enlightenment will abide by etiquette and law more willingly [15].

Kindergarten administrators, kindergarten teachers, children, logistics, parents should popularize etiquette knowledge and education, continually learn and practice it, integrate etiquette into everyone's daily life, thereby building a harmonious campus of etiquette.

\subsubsection{Etiquette supervision and implementation}

Etiquette education allows everyone to understand how to operate, but to guarantee the actual use and normalization of etiquette, we need a corresponding system for standardization. For example, a manual for kindergarten staff can be formulated to stipulate the dress, language, behavior requirements for each post. In addition, the kindergarten can also set up etiquette supervisors. Once there is violation of the ban, immediate persuasion and punishment will be given.

The kindergarten should integrate queuing, civilized language, and good posture into children's daily life. Through various learning corner arrangements and pictures and nursery rhymes delighted to hear and see, nurture children by etiquette in a subtle way, so that they consciously abide by social rules, thus forming good atmosphere.

3.3 Five levels: all-round implementation and continuous practice

ISSN: 0010-8189 
Everyone in the kindergarten is etiquette practitioner, and only when everyone treats others with etiquette, the entire kindergarten is an etiquette-based kindergarten. However, in the specific implementation process, the division of labor for each position is different, so the etiquette content involved is also different.

\subsubsection{Management-the platform builder of the "etiquette-based" kindergarten}

The chairman of the board, shareholders, and kindergarten directors are important personnel involved in "etiquette-based kindergarten management", because they determine the kindergarten's running philosophy, development idea, working atmosphere as well as the recruitment and appointment of teachers.

\subsubsection{Administrators must lead by example}

First, administrators themselves should have appropriate image and behavior, treat others with courtesy, and lead by example. Just as the below follows the behavior of the above, the administrators' behavior in society provides an observation object for kindergarten teachers, parents, and children.

On June 11, 2020, the shareholders of an international kindergarten in XX town directed 2 men and 1 woman to assault the head teacher and financial staff of the top class, which was just because the two teachers wanted to refund the parents who did not bring the payment list, causing dissatisfaction among shareholders. The kindergarten teachers went on strike to defend their rights, and 200 children were forced to take holidays. This has also led to a trust crisis between parents and the kindergarten. Some parents in the WeChat parent group commented: Such a school run by a black contractor does not respect the teacher at all, and we have to refund the fee.

The soul of a kindergarten is the kindergarten teacher. In June 2020, by issuing online questionnaires, the author surveyed parents' perceptions of kindergarten etiquette education. The survey received a total of 144 valid questionnaires. The data shows that when parents choose kindergartens, what they value most is not the kindergarten environment, food, and accommodation conditions, but the quality and teaching level of the kindergarten teachers. In other words, kindergarten teacher is a critical factor in parents' decision on which kindergarten to choose. Therefore, administrators must establish the concept of "respecting teachers and valuing education", create an atmosphere of mutual respect.

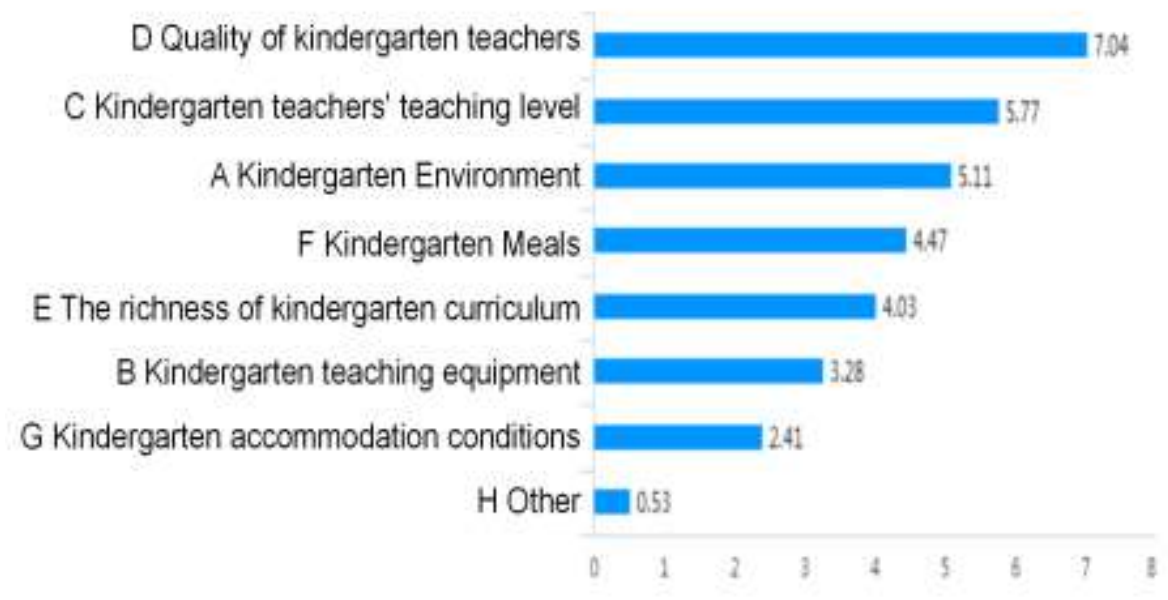

Fig 1: The factors which influencing parents' choice of kindergarten

3.3.1.2 Strictly check the entry of kindergarten teachers

To build a high-quality kindergarten, excellent management team and teachers team are a must. In many cases, a person's outstanding performance at work has a lot to do with his own instinct. As Stephen Curtin said: "The personality, temperament, uniqueness, creativity, and level of participation of employees are determined by the employees themselves, not their employers; she smiles "spontaneously", she "spontaneously" refuses to make fun

ISSN: 0010-8189

(C) CONVERTER 2020

www.converter-magazine.info 
with colleagues in front of customers; she "spontaneously" provides customers with more considerate services. When employers cannot find these attributes through enforcement, they can hire those with these attributes. This is why companies with the highest customer satisfaction put the most effort into employee selection."[16].

Therefore, when recruiting kindergarten teachers, kindergartens must strictly control the entry point, and grumpy kindergarten teachers who have no ethics and style, shout obscenities and show violent tendencies should never be recruited into kindergartens. In the event of an accident, not only the reputation of the entire kindergarten will be destroyed, but irreparable losses and situations are possible. In 2016, a kindergarten teacher acupunctured children in $\mathrm{XX}$ town, triggering a great disturbance on the Internet and causing a great negative impact on the kindergarten. Even if it has been nearly four years, parents in nearby communities still remember this matter whenever they mention the kindergarten and will remind others not to sign up easily.

\subsubsection{Solve the worries of kindergarten teachers}

"Protocol of banquet" says: All courtesies will be returned. Only when administrators give employees what they want can they truly stimulate employee enthusiasm, and employees will give customers what they want. Employees with a sense of belonging and happiness will naturally give warm smiles, sweet words, and kind care to the children. "Book of Rites" says: "The ministers do their best to contribute to the country, and the ruler must repay them with title and salary. Therefore, the ministers will do their best to serve the country, thereby bringing national security and peace." If the kindergarten wants to establish invincible team, but inferiorly repays the employees, making the employees can't even guarantee their survival, such kindergartens will not only lose talents, but also have difficulty to grow.

At the end of 2019, the "Elephant Mountain Educational Think Tank" and "Kindergarten Teacher Pocket" launched the "Survey on the Survival Status of Kindergarten Teachers in China". More than 1,500 kindergarten teachers from 30 provinces across the country participated in the survey. The survey objects covered groups of kindergarten teachers from different types of kindergartens, with different teaching experience, different income levels and other measurement dimensions. Seen from the survey results, low income has become the most dissatisfied point among kindergarten teachers.

Seen from the specific income data, teachers in private inclusive kindergartens have the lowest income in overall. $68.9 \%$ kindergarten teachers have a monthly income of less than 3,000 yuan, which is much higher compared to public kindergartens and private non-inclusive kindergartens. Teachers in public kindergartens have the highest income in overall, with $56.5 \%$ kindergarten teachers earning more than 3,000 yuan a month.[17]

Therefore, kindergartens can appropriately increase the salary of kindergarten teachers, so that they can concentrate on early childhood education; provide learning and promotion opportunities, so that teachers have more confidence in future career planning; provide training in handling interpersonal relationships, so that teachers live in harmony with the kindergarten, parents; create a good working atmosphere, keep kindergarten teachers away from internal intrigues, and reduce the internal friction of the kindergarten.

\subsubsection{Establish a clear reward and punishment system}

From the perspective of management, without the management support and institutional guarantees, it is difficult to implement new initiatives. To establish a kindergarten managed by etiquette, the kindergarten needs to set up a supervision team and corresponding grading rules, conduct $6 \mathrm{~S}$ management of the kindergarten environment, and evaluate teachers' image, professional ethics, words and deeds.

In addition, the salary of kindergarten teachers should be treated differently, and those who are willing to innovate teaching content and teaching methods should be rewarded. If there is no difference between those doing well and poorly, teachers will lack the enthusiasm for self-renewal. Of course, the reward system cannot be exclusive. As long as the teachers meet the standard, there is a chance to win prizes. Rewards with quotas are easy to cause intrigue among colleagues, resulting in internal consumption of resources. Such wrong atmosphere is adverse to the long-term development of the kindergarten. For example, due to grudges between kindergarten teachers in a kindergarten in Henan, a kindergarten teacher poisoned the children's food to retaliate against colleagues, causing 23 children to be collectively poisoned.

\subsubsection{Kindergarten teacher-the leader of etiquette-based kindergarten}

ISSN: 0010-8189 
Kindergarten teacher is a factor that parents particularly care when choosing a kindergarten for their children. The quality of kindergarten teachers and the teaching level directly affect children's learning experience.

\subsubsection{Excellent teaching quality}

Based on the author's research, it is found that what parents value most is not teaching ability nor teaching methods of kindergarten teachers, but whether the kindergarten teachers have teaching qualities such as affinity, patience, and respect for parents and children. The kindergarten teacher is faced with a group of 3-6 year old children whose bodies and IQ are immature. In the face of children's crying and childish language, whether teachers can avoid judgment by adult standards, especially avoid using language and behavioral violence to harm children is particularly critical. Only teachers who respect children can cultivate confident and loving children. According to the psychologist Satya, "There is no stupid child in the world, but what he knows is different from yours." Therefore, kindergarten teachers should accept the uniqueness of each child and teach students in accordance with their aptitude.

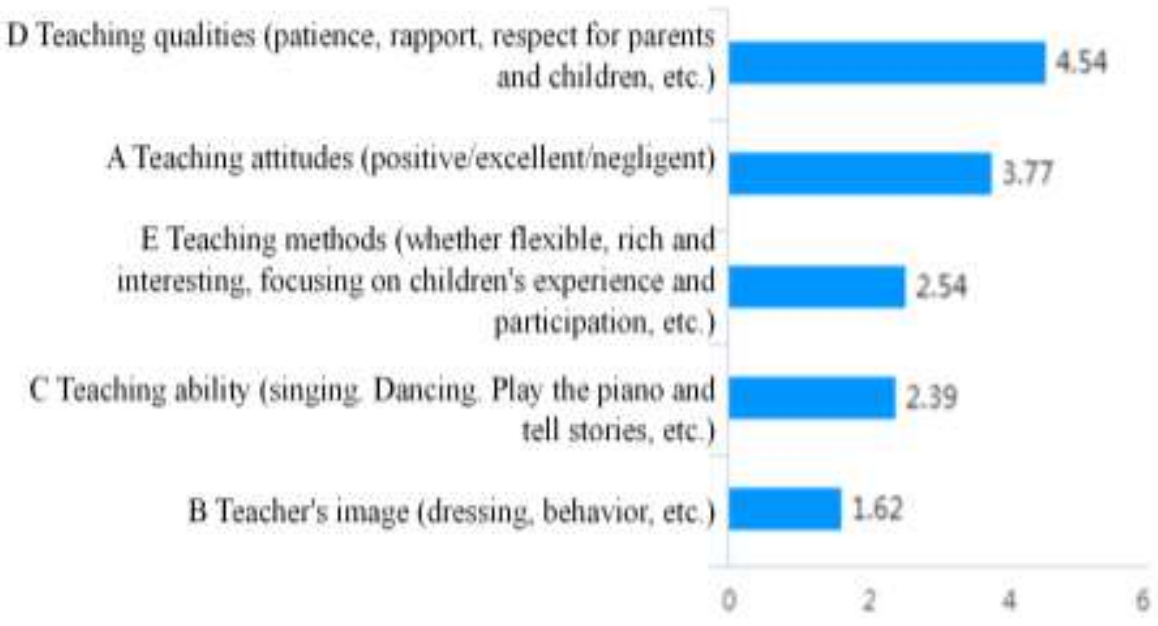

Fig 2:The ranking of teachers' abilities from the perspective of parents

3.3.2.2 Scientific teaching methods

Children's learning is based on direct experience in games and daily life [18]. Kindergarten teachers should maximally support and meet children's needs for gaining experience through direct perception, practical operation and personal experience. The following forms of teaching can increase children's learning experience and help children perceive growth and meaning of life.

\subsubsection{Increase the sense of ceremony}

Implementation of ceremonies comes with strong influence and appeal, which can cultivate identity behavior, stimulate the enthusiasm for forging ahead, and also create psychological balance and adjustment effect. Certain ceremonies and rites can strengthen social affinity and positively influence people's socialization. [19]

During various festivals such as Tomb-Sweeping Day and Mid-Autumn Festival, kindergartens can let children feel the festival atmosphere and the charm of traditional culture in real situations through the kindergarten layout, knowledge popularization, and design of various interesting activities. According to the author's research, $87.84 \%$ parents believed that kindergartens should hold various ceremonial activities, so that children can learn corresponding knowledge through the experience, deepening the understanding and memory of culture.

By constructing children's possible lives, children can survive and develop better, and truly become the subject of real life rather than passively follow real life. [20] 


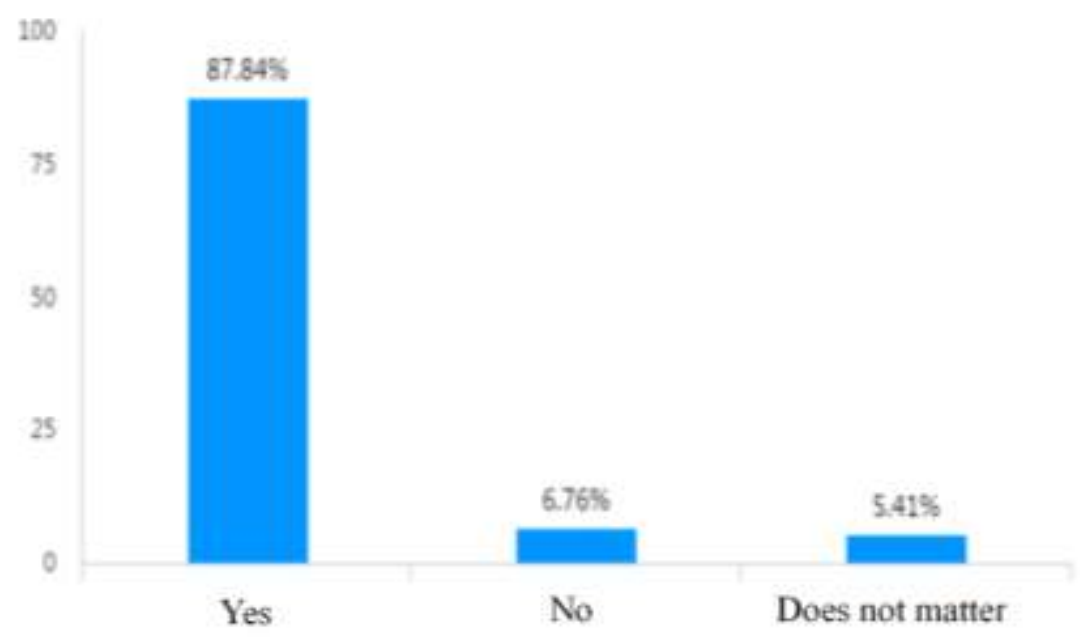

Fig 3: Is it necessary for kindergartens to carry out various ceremonial activities

3.3.2.4 Create a relaxed educational environment

Children are lively and active, with desire to try everything. Kindergarten teachers should create a relaxed learning atmosphere and environment for children and allow them to make mistakes. In such an environment, children do not have to worry about being scolded or punished, but dare to try boldly. At this time, kindergarten teachers must first properly handle their own emotions. Only by justly expressing emotions can they treat children with "gentle voice and attitude".

For example, "children's language skills are developed amid communication and use. A free and relaxed language communication environment should be created for children, encourage and support children to communicate with adults and peers, so that children want to speak, dare to speak, like to speak and can get a positive response therefrom."

\subsubsection{Integrate etiquette education into one-day life}

A day's life in a kindergarten is an important way for children to experience learning activities. Kindergarten teachers should integrate etiquette education into the children's day life, so that children can develop good etiquette in a subtle way.

For example, children should take the initiative to greet teachers and classmates when they enter the kindergarten in the morning; take the initiative to line up when eating and drinking; keep quiet during lectures and lunch breaks; raise their hands when they have doubts or questions; stand up when answering teacher's questions; use "please, thank you" and other civilized terms when communicating with others. In this way, we can cultivate polite little gentlemen and ladies with independent thinking.

\subsubsection{Set good examples}

Kindergarten teachers' words and deeds are imitation object for children. Therefore, kindergarten teachers should be courteous in interaction with colleagues, children, and parents, and set a good example for children.

Interpersonal communication and social adaptation are the main content of children's social learning and the basic way for their social development. In interaction with adults and peers, children not only learn how to get along with others, but also learn how to view themselves and others, thus constantly developing their ability to adapt to social life. Good social development exerts an important impact on children's physical and mental health and development in all aspects.

In today's information age, interpersonal communication has extended from offline to online. Kindergarten teachers also need consciously maintain their online image, especially the image on WeChat, an increasingly used communication tool for the masses. The author's research found that some kindergarten teachers would post

ISSN: 0010-8189 
information on Wechat Agents in the Moments of Friends. Such practice makes some parents feel that the teacher's salary is too low to make them focus on teaching. Moreover, the result is not fine regardless of whether parents buy the products or not. Some teachers post some non-mainstream selfies, which will make parents worry that the teachers are too fashionable, have no patience to take care of their children, and set wrong examples among the children. Some teachers even post on Moments of Friends to pray for smooth passage of the kindergarten teacher qualification examination. Parents would concern that the kindergarten teacher without professional qualification certificate should serve as a teacher for their children in the kindergarten, and thus doubt the teaching level of the kindergarten.

\subsubsection{Parents-participants of the "etiquette-based kindergarten management"}

When every family is benevolent, one country fosters benevolence; when every family upholds courtesy, one country promotes courtesy [21].Family is the core hub for social operation. Only when the family is harmonious and peaceful can the healthy operation of the macro society have solid support and the healthy growth of individuals can be firmly guaranteed. [22].The family is the "nurturing place" of human nature and the "breeding ground" of "ethics"; "Etiquette education" is not only an important part of "family education", but also the basic way to nurture a good family tradition. Family style exists in the daily life of the family and is reflected in the gestures and expressions of family members.22Parents should "create a warm interpersonal environment for children, so that children can fully feel family affection and love, and form positive and stable emotions. Also, parents should help children develop good living and hygiene habits, and improve self-protection ability."

\subsubsection{Parents should communicate with their children on an equal footing}

In recent years, there are more only children in China, and there appears a phenomenon that parents and grandparents nurture one child together through generations. This tends to make the child overprotected and become the little emperor and little princess of the family. We shall not run the whole show in terms of children, and it is best to communicate with children on an equal footing. Parents should respect their children's ideas and encourage children to practice personally, which is more conducive to children's growth. "When we reach equality, the family will become stronger and we will cultivate more competitive descendants."[23].

Children with immature physical and mental development require careful care and attention from adults. However, there should be no excessive protection and control to avoid depriving children of the opportunity to learn independently, making children over-dependent, and affecting their development in initiative and independence.

\subsubsection{Learn about parenting knowledge through multiple channels}

Many parents assume the role of parents for the first time. Coupled with busy work, their parenting knowledge is insufficient. Therefore, communities and kindergartens should regularly organize parent training classes, and invite relevant experts, professors to pass on scientific parenting concepts and educational methods to parents, so as to achieve a model of combined rearing by home, kindergarten, and society.

At present, kindergartens have set up many home cooperation channels, including institutional channels such as parent schools and parent committees, as well as project channels such as parent open day activities, parent-child activities, parent meetings, home visits, and home contact lists, as well as information channels such as class WeChat groups, QQ groups, WeChat platform. [24] Parents should participate more in kindergarten activities and set a good example for children in a courteous manner.

\subsubsection{Children-practitioners of "etiquette-based kindergarten management"}

Managing the kindergarten with etiquette and giving children the utmost respect and freedom does not mean we should allow children to lack discipline, indulge themselves, or completely control their words and deeds so that they become disciplined bodies. On the one hand, we should respect children, give them the right to express and maintain themselves reasonably, and let them develop independent thinking; on the other hand, we should teach children the necessary rules in interpersonal communication scenarios, let them integrate into the group and society, and do their best to contribute to a better and more harmonious society.

Kindergarten children are young and have a weak sense of autonomy. Most of the behavior and learning contents demand guidance from the teacher. The kindergarten teacher should integrate all the etiquette content into the children's daily life in a form that children love to hear and see. Etiquette should be permeated in the kindergarten's day-to-day process, mainly reflected in queuing and civilized language.

ISSN: 0010-8189 
Health: For example, create a warm and relaxed psychological environment to allow children to form a sense of security and trust, and maintain their physical and mental health. Respect children's self-esteem, and at the same time, pay attention to maintaining children's physical health. Help children learn to express and control emotions properly, that is, let children learn to express correctly without suppressing their emotions. "We should pay attention to children's posture and help them form correct postures. For example, remind young children to maintain correct standing, sitting, and walking postures. Abnormalities in bone development such as splay feet, bandy legs, humpback, etc., should receive medical treatment in time."

Independence: Everyone as an independent individual must have independent thinking and survivability. One should have one's own opinions, rather than follow the trend, go with the tide. Parents and kindergartens should provide children with independent space, avoid stifling children's enthusiasm, do not devalue children's self-esteem, and let children learn to take care of themselves and independently solve the problems within their power.

Harmony: Everyone as a member of society needs to learn the corresponding rules of interpersonal communication. There is need to communicate with others in a more appropriate way, convey respective views, and maintain good interpersonal relationships.

It is necessary to obey the rules in public, because according to Goffman's point of view, "people with higher status are those who pay the most attention to etiquette, and therefore we should exclude those who cannot properly implement etiquettes."[25] Hence, we must teach children to be independent, self-pleasurable and self-respectful in the private sphere. However, in the workplace and public sphere, we need to teach children to follow the rules, express themselves appropriately, and conduct interpersonal communication in a suitable way.

\subsubsection{The logistics team-the guarantor of etiquette-based kindergarten management}

Security personnel give the first impression of etiquette-based kindergarten management, whose etiquette literacy is particularly important. Medical staff deal with children every day, who are also the observation objects for parents and children. The kitchen staff and cleaning staff must at least be neatly dressed, with amiable attitude and graceful demeanor. All these personnel are part of the kindergarten. Only when everyone treats others with etiquette, the entire kindergarten can be a beautiful, harmonious and warm etiquette-based kindergarten.

\section{Conclusions}

In etiquette-based kindergarten management, what we want to achieve is a state of "pleasure between people and me". First, everyone should treat oneself with courtesy, cherish one's life and rights as a person, cultivate one's moral character, possess the ability to make oneself physically and mentally happy, and play a good role by doing good turns. At the same time, as a member of the society, we should practice etiquette rules for interaction with others, which will help establish harmonious interpersonal relationships. In this way, the individual is in harmony with oneself, the individual is in harmony with others, and the whole society is more harmonious and orderly.

In addition, by learning etiquette culture, kindergarten administrators, kindergarten teachers, logistics can not only cultivate personal accomplishment and face work and life with more enthusiasm, but also reduce internal friction, improve work efficiency, and enhance the kindergarten image. Of course, construction of etiquette-based kindergarten is inseparable from the participation and practice of children's families. Through parent classroom, family-kindergarten mutual assistance, participation in various ceremonies, etc., parents can master more parenting knowledge and skills, and create a warm, courteous and loving family atmosphere for children, so that children can subtly learn skills to live in harmony with themselves and others.

In short, kindergartens, families and society should work together to create a warm, equal, loving, and courteous family and collective living atmosphere for children, establish good parent-child relationships, teacher-student relationships, and peer relationships, so that children can gain a sense of security and trust in positive and healthy interpersonal relationship, develop sufficient self-esteem and self-confidence to form an independent personality. Moreover, we should let children learn to abide by and use social etiquette rules through good social environment and cultural edification, and enhance their identity and sense of belonging towards national culture, so that they do best to contribute to a better and more harmonious society. 


\section{References}

[1] Z.G. Yang, "Rites and the creative transformation of tradition." Fudan Journal (Social Science Edition), vol. 3, pp. 38-43, 1993.

[2] W.J. Wang, "Translation and interpretation of the Book of Rites.” China Bookstore. pp. 667, 2016.

[3] L. Peng Translation, Rites of Passage. China Book Bureau, vol. 6, pp. 14, 2012.

[4] X. Han. "Exploration of the system of ritual governance thought of Duke Zhou," Journal of the Party School of the CPC Ningbo Municipal Committee, vol. 3, pp. 42-49, 2020.

[5] Z.G. Yang, "Research on Chinese Ritual System," East China Normal University Press, pp. 2, 2000.

[6] X.T. Fei, Native China. People's Publishing House, pp. 62, 2008.

[7] Y.H. Jiang. "On the Contemporary Significance of "Ritual Rule"”. Red Flag Manuscript, pp. $20,2014$.

[8] Propaganda Department of the CPC Central Committee. Thirty Lectures on Xi Jinping's Socialist Thought with Chinese Characteristics for a New Era. Beijing: Learning Press, 2018.

[9] X. Fang, J. Chen, "Traditional life rituals: how the "past" participates in constructing the "present"," Social Science Journal, vol. 5, 2020.

[10] L. Peng, “Ancient Chinese Etiquette Civilization,” China Book Bureau, vol. 4, pp. 14, 2013.

[11] General Office of the CPC Central Committee and General Office of the State Council. Opinions on the implementation of the project of inheritance and development of Chinese excellent traditional culture People's Daily, vol. 6, pp. 01-26, 2017.

[12] Bi Tianyun, "Rites: the basic norms of social operation, Symposium: An exploration of traditional Chinese sociological concepts, in Fujian Forum - Humanities and Social Sciences Edition,” No. 4, 2018.

[13] Zheng Xuan, ites of Justice [M]. Beijing: China Book Bureau, 1980, p. 1609.

[14] M.Z. Zhang, "lections on the Theory of "Rites" in Ancient China," Journal of Xi'an Jiaotong University (Social Science Edition), vol. 7, 2018.

[15] C. Jiang, "Chinese traditional values of human rule, moral rule, ritual rule and rule of law," Journal of Jiangsu Administrative College, vol. 1, 2019.

[16] S. Curtin, Y.T. Wang. "Service excellence: seven simple ways to take customer service from mediocrity to excellence," Enterprise Management Press, vol. 4, pp. 11, 2014.

[17] Da Xiang Shan Education Think Tank, Survey Report on the Survival Status of Kindergarten Teachers in China 2019: Over 90\% of Kindergarten Teachers Want to Change Careers. pp. 12-27, 2019.

[18] Ministry of Education,3-6 years old children's learning and development guide. pp. 9, 2012.

[19] Z.G. Yang, "The history of Chinese rites of passage," Fudan Journal (Social Science Edition), vol. 6, 1995.

[20] N. Zhang, "Reconstruction of kindergarten curriculum goals under the orientation of life values," Educational Research and Experiment, pp. 1, 2018.

[21] W.J. Wang, "Translation and Interpretation, Translation and interpretation of the Book of Rites. Chinese book bureau," pp. 810, 2016.

[22] T.Y. Bi, "Rites: the basic norms of social operation," Fujian Forum - Humanities and Social Sciences Edition, vol. 4, 2018.

[23] V. Satya, C.L. Yi, D.M. Ye, "How the New Family Shapes People," Beijing: World Book Publishing Co. Beijing, pp. 393, 2018.

[24] F. Peng, "Moral education in kindergartens under the guidance of the educational ideology of "building moral character"," Preschool Education Research, vol. 7, pp. 89-92, 2020.

[25] R.B. Collins, J.R. Lin, P. Wang, L.J. Song, “Interactive ritual chain,” Beijing: The Commercial Press, pp. 386, 2019. 